\title{
O "Curso de Botânica Popular” ministrado por Joaquim Monteiro Caminhoá nas Conferências Populares da Glória (1876) ${ }^{1}$
}

\section{The "Popular Botanics Course" taught by Joaquim Monteiro Caminhoá in the Gloria Popular Conferences (1876)}

\author{
ALEX GONÇALVES VARELA \\ Universidade do Estado do Rio de Janeiro | UERJ
}

\begin{abstract}
RESUMO Temos como objetivo analisar a trajetória do botânico Joaquim Monteiro Caminhoá, em especial a sua participação nas Conferências Populares da Glória, quando no ano de 1876 foi o responsável por ministrar um Curso de Botânica Popular. De um total de dez aulas, apenas duas foram impressas e serão objeto de análise crítica. Os textos produzidos para o referido Curso deixam transparecer a contribuição do personagem para o processo de emergência e consolidação das ciências naturais no Império do Brasil.
\end{abstract}

Palavras-chave Joaquim Monteiro Caminhoá - botânica - Império do Brasil - popularização das ciências

\begin{abstract}
We aim to analyze the trajectory of the botanist Joaquim Monteiro Caminhoá, especially his participation in the Popular Conferences of Gloria, when in 1876 he was responsible for teaching a Popular Botany Course. Of a total of ten classes, only two were printed and will be subject to critical analysis. The texts produced for this course show the contribution of the character to the process of emergence and consolidation of the natural sciences in the Brazilian Empire.
\end{abstract}

Keywords Joaquim Monteiro Caminhoá - botany - Empire of Brazil - popularization of science

\section{Introdução}

Joaquim Monteiro Caminhoá foi um dos mais importantes homens de ciência que atuaram no Império do Brasil, tendo inclusive uma carreira consolidada e reconhecida internacionalmente. Ele atuou em instituições científicas, foi sócio de diversas sociedades, e publicou diversos livros e artigos. 0 estudioso se dedicou a produzir conhecimento científico sobre questões médicas e botânicas. Contudo, sua trajetória acadêmica ainda não foi devidamente estudada, e suas produções ainda não foram analisadas profundamente. Dessa forma, há lacunas que precisam ser preenchidas pelos estudiosos que se dedicam a pesquisar as relações ciências e trajetórias, e caminhos amplos e profícuos que merecem ser explorados e estimulam novas reflexões. ${ }^{\text {? }}$

Temos como objetivo recuperar a trajetória do cientista Caminhoá, em especial a sua participação nas Conferências Populares da Glória, quando ministrou um Curso de Botânica Popular. Analisaremos as duas primeiras participações do botânico no referido Curso, uma vez que os textos foram impressos. Tais estudos deixam transparecer a contribuição do personagem para o processo de emergência e consolidação da Botânica no Império do Brasil. 


\section{A trajetória do médico-botânico Joaquim Monteiro Caminhoá}

Caminhoá nasceu na cidade de Salvador, então província da Bahia, em 21 de dezembro de 1836. Era filho de Manuel José Caminhoá e Luiza Monteiro Caminhoá, e irmão de Luiz Monteiro Caminhoá. Faleceu, no Rio de Janeiro, em 28 de novembro de 1896.

Caminhoá ingressou na Faculdade de Medicina da Bahia (FMBa) para realizar os estudos superiores no ano de 1853. A Escola baiana foi a primeira a ser criada no momento em que a Corte portuguesa realizou a sua transferência para a América, em função das invasões francesas no território português. 0 Príncipe-Regente D. João fundou a Escola de Cirurgia da Bahia na cidade de Salvador pela decisão régia de 18/02/1808, sediada no Hospital Real Militar da Bahia, localizado no antigo prédio do Colégio dos Jesuítas.

A passagem de Caminhoá pela Faculdade coincidiu com a alteração da vida institucional da mesma, decorrente da sanção de um novo estatuto em 28 de abril de 1854, conhecida como Reforma Bom Retiro, que alterava a administração da instituição e aumentava 0 quadro docente. A partir daquela data a FMBa perdia a autonomia garantida pelo estatuto provisório de 3 de outubro de 1832. Foram suprimidos os direitos de confeccionar os seus regulamentos internos, de mudar a seriação das matérias, de dispor de suas taxas e emolumentos em favor da biblioteca, de eleger 0 diretor e de sugerir a.o Poder Legislativo os créditos necessários à melhoria dos laboratórios e gabinetes da Faculdade. Foi criada uma nova categoria docente, a de "Opositor", e suprimida a de "Substituto". 0 curso médico passou a ter 18 cadeiras, quatro a mais do que anteriormente -foram acrescentadas as cadeiras de Anatomia Geral e Patológica, Patologia Geral, Química Orgânica e Farmácia..$^{-}$

Foi, portanto, nessa instituição que Caminhoá obteve a sua formação, tendo defendido a sua tese de doutorado no ano de 1859, intitulada "A febre amarela e o colera morbus serão provenientes de um envennenamento miasmático? Da medicação hydrotherápica; Exame e solução das principaes questões sobre a anesthesia e na therapêutica cirúrgica; Ozona, sua natureza, propriedades e preparação".

Após a formação superior, ele ingressou no Corpo de Saúde da Armada, prestando serviços como segundo cirurgião $2^{0}$ tenente, e posteriormente como cirurgião de divisão graduado, e primeiro cirurgião $1^{0}$ tenente, em hospitais e navios juntamente com outros opositores e lentes da Faculdade de Medicina do Rio de Janeiro. Caminhoá participou da Guerra do Paraguai (1864-1868). A seguir ao término do confronto reformou-se com o posto de primeiro cirurgião $1^{0}$ tenente médico, tendo sido agraciado com as medalhas comemorativas da Campanha Oriental de Paissandu, da rendição das forças paraguaias em Uruguaiana, e da Campanha do Paraguai.

Não sabemos precisar a data que Caminhoá veio fixar residência na Corte do Rio de Janeiro, capital do Império do Brasil. Nesta região estavam sediadas as principais instituições científicas, como o Museu Real, o Jardim Botânico, a Faculdade de Medicina, o Instituto Histórico e Geográfico Brasileiro, a Academia Imperial de Medicina, entre outras, lugares de produção de conhecimento científico.

A carreira médica profissional de Caminhoá enquanto docente e pesquisador teve início, quando ele foi nomeado, mediante concurso, no ano de 1861, à vaga de opositor da sessão de ciências acessórias da Faculdade de Medicina do Rio de Janeiro. Desde a sua criação, em 1854, o lugar de Opositor foi uma posição que pouca atração exercia sobre os jovens médicos, sendo, portanto, pouco disputada. Em vários concursos o número de candidatos foi insuficiente para o preenchimento das vagas oferecidas. 0 salário de 1:200\$000 mais uma gratificação de igual valor era considerado baixo. Por sua vez, um professor catedrático recebia um salário de 2:000\$000 mais uma gratificação de 1:200\$000. Salienta-se também que, dentro da hierarquia acadêmica, a subordinação do Opositor ao seu respectivo catedrático era absoluta. Suas atividades, determinadas anualmente pela Congregação da Faculdade, eram eventualmente de ensino. 0 Opositor era uma espécie de serviçal do catedrático. ${ }^{4}$

Ainda que à função de Opositor Ihe fosse atribuída marca do desprestígio, esta era indispensável para qualquer pretendente a ocupar uma das cátedras da Faculdade. A renovação do quadro docente da Faculdade de Medicina do 
Rio de Janeiro começa a ocorrer a partir da reforma do ensino de 1854. Esta renovação, imposta pelo jubilamento ou morte de vários professores, indicava a passagem da primeira geração de catedráticos da Faculdade que ascendeu ao cargo na década de 1830. Entre 1854 e 1865 quase todos os antigos professores foram substituídos por Opositores nomeados pelo governo por meio de um intrincado jogo de cooptação e influência política. $\underline{5}^{5}$

No ano de 1871, Caminhoá apresentou-se para o concurso convocado para a cadeira de Botânica Médica. Na ocasião apresentou a tese "Das plantas tóxicas do Brasil", e obteve a aprovação, passando de opositor da seção de ciências acessórias à lente catedrático.

A Cadeira de Botânica e Zoologia foi implementada na grade curricular do curso de medicina com a execução da Reforma de 1832. Ela seria ensinada no primeiro ano da Faculdade e ficaria a cargo do professor Francisco Freire Allemão de Cysneiros (1797-1874). Este último foi responsável pelo ensino da mesma no período de 1833 a 1853. E, ao que parece, não houve substituição até 0 ano de 1871, ficando a referida Cadeira sem o seu Lente Catedrático.

Sublinhamos que Freire Allemão foi um dos mais proeminentes homens da Botânica no Império do Brasil. Ele foi um dos primeiros naturalistas brasileiros a consolidar sua carreira no universo profissional do Brasil do novecentos. Sempre esteve envolvido nas principais iniciativas em prol do fortalecimento das ciências naturais do nosso país, como a criação de instituições e periódicos especializados. Uma das suas atuações mais marcantes foi a sua participação na Comissão Científica do Império (1859-1861), também conhecida como Comissão das Borboletas, tendo sido presidente da mesma e chefe da Seção de Botânica, quando desenhou e descreveu inúmeras espécies de plantas. $\underline{6}$

Por sua vez, com a Reforma Bom Retiro, levada a termo pelo decreto $n^{0} 1.387$, de 28/04/1854, a supracitada Cadeira passaria a integrar a Secção de Ciências Acessórias, e seria lecionada no segundo ano. Ainda que novas reformas do ensino médico fossem implementadas, os estudos botânicos e zoológicos permaneceriam sendo ensinados no segundo ano. ${ }^{ }$Após obter a cátedra no ano de 1871, Caminhoá regeu-a até 1881, quando se jubilou da instituição.

A carreira médica de Joaquim Monteiro Caminhoá foi marcada pela opção por uma atividade estritamente médica que em nenhum momento foi desdobrada em carreira política ou na ocupação de cargos públicos, fato comum entre os membros da elite médica. Esta é a principal singularidade da carreira de Caminhoá se comparada com a dos primeiros catedráticos da Faculdade de Medicina, e que 0 aproxima da carreira do também médico João Vicente Torres Homem. $\underline{.}$

Em 1873, em viagem pela Europa, visitou vários jardins e hortos científicos, cujas observações resultaram num trabalho intitulado "Relatório sobre os jardins botânicos", que foi apresentado à Secretaria de Estado dos Negócios da Agricultura, Comércio e Obras Públicas, e será nosso objeto de análise no terceiro capítulo. $\underline{9}$

Em 1879 concorreu à cátedra de História Natural no Internato do Imperial Colégio de Pedro II, na cidade do Rio de Janeiro. E, na ocasião apresentou a tese intitulada "Família das Euphorbiáceas". Caminhoá foi aprovado, e regeu a cátedra de 1880 a 1889.

Salienta-se que foi também na década de setenta do oitocentos que apareceria no cenário da Botânica nacional o naturalista João Barbosa Rodrigues (1842-1909). Este último, no ano de 1870, surpreendeu a comunidade científica nacional com a apresentação de uma obra sobre orquídeas brasileiras, em três volumes e com descrições em latim e francês. Rodrigues era um amador, pois não realizou curso superior algum, fato que inclusive gerou restrições a ele, sobretudo da parte de Ladislau Netto, diretor do Museu Imperial na época. Contudo, o "botânico" contou com o apoio de Guilherme Schuch, barão de Capanema, que não mediu esforços para incentivar a carreira de Rodrigues como botânico profissional, proporcionando-lhe suporte moral e financeiro em momentos difíceis. Barbosa, sob o patrocínio do Barão, foi comissionado pelo governo brasileiro para explorar o vale do rio Amazonas, para realizar levantamento taxionômico do gênero Palmarum. Observou, assim, as espécies em seus respectivos ambientes naturais, e as reproduziu em seus desenhos. Por sua vez, graças à influência de Capanema, foi chamado pelo governo imperial no ano de 1883 para dirigir o recém-criado Museu Botânico do Amazonas. E, em 1892, foi nomeado diretor do Jardim Botânico do Rio de Janeiro. Suas atuações lhe conferiram crédito para que a comunidade científica o reconhecesse como um grande naturalista..$^{10}$ 
Retornando à trajetória de Joaquim Monteiro Caminhoá, convém registrar que ele também integrou diversas sociedades científicas. Ele candidatou-se à Academia Imperial de Medicina em 11 de abril de 1864, submetendo para sua admissão a memória intitulada "Sobre aparelhos anestésicos e, particularmente, sobre um inalador adjuvante para os casos operatórios em que não houver cirurgião ajudante". E, não era qualquer pessoa que conseguia adentrar os quadros da Academia. Para ser admitido à condição de membro titular ou adjunto, posição que dava direito a participação efetiva na vida institucional, era conquistada por meio de uma eleição, em que os sócios honorários eram escolhidos entre médicos e cientistas nacionais e estrangeiros de reconhecida competência. Mas, independentemente do critério de seleção, todos os candidatos a sócios tinham que ter seus nomes obrigatoriamente aprovados pelo governo. Caminhoá teve a sua memória julgada, aprovada, e o médico foi admitido como sócio.

Além disso, a AlM funcionou como um órgão corporativo, garantindo privilégios para seus membros e criando mecanismos de definição de uma medicina oficial. Como bem mostraram Luis Otávio Ferreira, Marcos Chor Maio, e Nara Azevedo ${ }^{11}$, 0 artigo 7 do Estatuto da AIM determinava que "o lugar de membro da Academia é um título de recomendação para todas as comissões ou empregos relativos ao exercício da medicina; e a ela não poderão ser admitidos aqueles médicos, cirurgiões e farmacêuticos que tenham afixado nos lugares públicos ou divulgado pela imprensa anúncios sobre curativos que fizerem ou sobre a distribuição e venda de remédios que não tenham previamente submetido ao exame e aprovação da AIM, ou de qualquer das faculdades de medicina do Império. As suas memórias serão rejeitadas sem discussão". Tal artigo, mencionado pelos autores supracitados, instituía um monopólio profissional baseado exclusivamente no pertencimento aos quadros de sócios. Isso significava a destinação a estes médicos de parte substantiva do reduzido mercado de trabalho da época, os cobiçados postos públicos. Muito mais do que subsídios financeiros, este privilégio selou a aliança entre os médicos da AIM e o Estado imperial, imprimindo à medicina um caráter oficial.

Em torno da Academia de Medicina, segundo Flávio Coelho Edler ${ }^{12}$, uma elite médica empenhou-se na produção de um conhecimento original sobre a patologia brasileira. Desde sua criação, até meados do século, ela conseguiria monopolizar duas importantes tarefas: ao mesmo tempo que se impusera como instrumento da política imperial da saúde pública, tornara-se o principal árbitro das inovações médico-científicas, contribuindo tanto para sancionar novas tecnologias em diagnóstico e terapêutica quanto novos conceitos e teorias estritamente voltados para o conhecimento da patologia brasileira. Ainda seguindo os passos do historiador das ciências acima referido, tal como a Academia de Medicina de Paris, que lhe servira como figurino, ela oferecia prêmios em competições anuais, coletava e examinava informações epidemiológicas, administrava a vacinação antivariólica, auxiliando o governo em matéria de educação médica, polícia higienista e saúde pública.

Na Academia Imperial de Medicina, Caminhoá foi um participante ativo, integrando essa elite médica responsável pela produção de conhecimento, discorrendo sobre vários temas, como os vinhos naturais sob o ponto de vista higiênico e terapêutico. Apresentou também uma comunicação sobre a floresta de quinas verdadeiras da Barreira do Soberbo (Teresópolis, Rio de Janeiro), na qual destacou sua relação com a matéria médica, relatando o quanto insuficiente era a produção dessa rubiácea tendo em vista o número de doentes de impaludismo, como também tratou das vantagens daquela floresta para a silvicultura.

Joaquim Monteiro de Caminhoá foi um dos fundadores da Associação Brasileira de Aclimação, criada em 7 de maio de 1872, da qual foi também membro da seção de botânica (1872), secretário (1875), diretor (1876) da seção de botânica, e redator em chefe da Revista trimensal da Associação Brasileira de Aclimação, publicada por esta associação.

Participou da comissão, organizada em 1873 pela Sociedade Velosiana de Ciências Naturais, da qual também era sócio, para a revisão do Dicionário de Botânica Brasileira, baseado nos manuscritos deixados pelo médico e botânico Manoel Arruda da Câmara (1752-1811) e preparados pelo farmacêutico pernambucano Joaquim de Almeida Pinto. Salienta-se que a Velosiana ${ }^{13}$, reunida pela primeira vez em 27 de julho de 1850, foi um dos principais fóruns de discussão e divulgação de atividades e contribuições científicas no Brasil Império. A Sociedade tinha como fim "' "indagar, coligir e estudar todos os objetos pertencentes à história natural do Brasil; e juntamente averiguar e interpretar as palavras indígenas, com que forem designados" (artigo $\left.1^{\circ}\right) . \underline{14}$ 
Ao revisar a obra de Arruda da Câmara, os homens de ciência do Império do Brasil estavam recuperando a trajetória de um dos mais importantes naturalistas que atuaram no império português entre o final do século XVIII e o início do XIX. Câmara integrou a chamada geração de 1790, constituída dentre outros por homens de ciência que estavam preocupados com a modernização do Império, e acreditavam que por meio da produção do conhecimento sobre 0 mundo natural das colônias conseguiriam realizar tal empreendimento..$^{15}$

Por sua vez, Caminhoá, que foi um dos membros da comissão de revisão da obra de Arruda da Câmara, era um cientista do Império do Brasil que se dedicou a estudar a Botânica e a Medicina em instituições de ensino e pesquisa, integrar como sócio diversas academias científicas, publicar seus estudos, e participar de espaços de divulgação científica com o intuito de difundir as "luzes" das ciências pela sociedade brasileira do oitocentos. E, reconhecia a importância de Arruda da Câmara para o incremento da Botânica no Brasil.

Por sua vez, Caminhoá foi membro adjunto da comissão brasileira na Exposição Universal de Viena, realizada de maio a novembro de 1873, onde apresentou estudos sobre botânica médica, e foi também membro do júri do $4^{0}$ grupo do evento, o de substâncias alimentícias e de consumo como produtos de indústria. Neste mesmo ano participou do Congrés Médical Internationale de Vienne, como delegado do Governo do Brasil e vice-presidente da Seção de Quarentenas, quando apresentou uma memória sobre as quarentenas.

Caminhoá preocupava-se com a divulgação das suas pesquisas científicas em Memórias, Anais, Revistas, Periódicos, Boletins, livros, entre outros. Tal fato deixa transparecer a presença do ideal llustrado de "esclarecimento", a função "educadora" que os sábios e os letrados deveriam cumprir na sociedade. ${ }^{16}$

Foi membro da Sociedade Abolicionista da Escravatura, e um dos fundadores da Associação Beneficente da Corporação Docente do Rio de Janeiro.

A principal obra de Caminhoá intitula-se "Elementos de Botânica Geral e Médica", cuja primeiro volume, num total de três, foi publicado em 1877. Na Introdução da obra assim afirmou Caminhoá:

Este livro é o resultado de quase dezesseis anos de estudo e meditação; é o resumo de cinqüenta e nove compêndios e obras de diversos autores da Europa, Estados Unidos, Chile, Brasil, até os publicados há pouco tempo; como o do professor Afonso Wood, de New York, por ocasião da festa do centenário da Independência Americana, o do professor Bellinck, de Namur, (na Bélgica), vindo à luz em fins de 1870; o do professor Darchartre, cuja última parte se acha ainda no prelo, a "História das Plantas" do professor Bailon (da faculdade de Medicina de Paris), a Flora Braziliensis do Dr. Martius, além de outros mais, cuja publicação ainda não está terminada. ${ }^{17}$

Caminhoá argumentou que a razão que o motivou a redigir tal obra foi o fato de reconhecer que existem obras de Botânica que são muito resumidas e "não tratam de certos assuntos que tenho por indispensáveis, e, portanto, não servem por compêndios nos cursos superiores", ou então são obras extensas, "como o do sábio professor Julio Sachs", que "tratam apenas de parte da ciência, e servem para ser consultadas de preferência pelos que, sabendo a matéria, desejam nela aperfeiçoar-se". Assim, Caminhoá argumentou que elaborou um compêndio que estivesse "entre os primeiros e este do professor Sachs"..18

0 trabalho foi, segundo Caminhoá, apresentado e aprovado pela Faculdade de Medicina do Rio de Janeiro, e adotado como compêndio. $\stackrel{19}{E}$, foi também agraciado com o prêmio máximo concedido pelo Regulamento das Faculdades de Medicina do Império. Portanto, a publicação teve o apoio do governo imperial. Entre a aprovação e a publicação da obra passaram-se alguns anos. Tal fato possibilitou "retocálo- em alguns pontos, depois de tê-lo submetido à crítica de diferentes botânicos na Europa, os quais (...) não só me animaram, como aconselharam; e em alguns pontos fizeram-me conhecer 0 que a ciência tinha adiantado!". $\underline{20}$

Dentre os estudiosos a quem Caminhoá agradeceu estavam naturalistas e botânicos que apresentaram comentários críticos à obra, dentre os quais Adolpho Brogniart (1801-1876), Conde de Jaubert, Pierre Étienne Simon Duchartre 
(1811-1894), Henri Baillon (1827-1895), tendo deste último servido de referência a sua obra História das Plantas na parte fitográfica, e Ernest Germain de Saint Pierre (1815-1882).

Caminhoá informou que o público alvo da sua obra eram "os alunos das diferentes faculdades e escolas, os agricultores e amadores da Botânica". 21 Contudo, argumentou o professor da FMRJ, ter empregado "uma linguagem ao alcance de qualquer inteligência". 22

A utilização de estampas foi um dos destaques da obra, que segundo Caminhoá, são "meios de simplificar as explicações da História Natural e de torná-las facilmente compreensíveis". $\underline{2}$ Elas foram adquiridas junto à Casa Hachette \& Cia., em Paris, e que já tinham sido utilizadas em obras de outros autores. Utilizou também três mapas de geografia botânica. Assim, afirmou Caminhoá ter "seguido o exemplo de todos os botânicos, que, já encontrando feitas gravuras que lhes sirvam, embora já figuram noutras obras, fazem aquisição delas". ${ }^{24}$ Assim, ele afirmou ter tornado "instrutivo, claro e nítido" o compêndio produzido.

0 Compêndio, além de uma Introdução ao Leitor, contém oito partes, que são: 1) Prolegômenos; 2) Fitotomia; 3) Organografia; 4) Fisiologia; 5) Fitologia ou Classificação; 6) Teratologia e Patologia; 7) Estudo da distribuição dos vegetais no globo terrestre (geologia e geografia vegetais); 8) dos herbários.

A atuação de Caminhoá no campo científico lhe conferiu honras e prestígio, e lhe permitiu acumular créditos para futuras mercês e títulos. A honra estava sob o controle do soberano e quanto mais dele o súdito se aproximasse, mais tornava forte o reconhecimento do seu valor e serviço. Ele foi nomeado membro do Conselho do Imperador D. Pedro II, Comendador da Ordem da Rosa e da Imperial Ordem Austríaca de Francisco José, Cavaleiro da Ordem de S. Bento de Aviz, e recebeu o hábito de Cavaleiro da Ordem de Cristo. Caminhoá esforçou-se para se aproximar do Imperador, para ser um médico-botânico honrado e, assim, afastar-se da base da pirâmide social.

Joaquim Monteiro Caminhoá foi, portanto, um dos principais nomes da Botânica no Brasil do século XIX. Ele pertenceu a importantes instituições de ensino, como a Faculdade de Medicina do Rio de Janeiro, e o Imperial Colégio Pedro II, bem como a associações científicas, como a Academia Imperial de Medicina, e a Sociedade Velosiana. Publicou diversos artigos e participou de espaços de divulgação científica, como as Conferências Populares da Glória, momento em que buscou difundir as "luzes" da ciência pela sociedade.

\section{As Conferências Populares da Glória}

Na segunda metade do século XIX, era desejo da maior parte da elite brasileira pertencer ao chamado mundo civilizado, como destaca Karoline Carula. Naquele momento, o país precisava "estar tão civilizado" quanto às sociedades europeias. Para que esse patamar fosse alcançado, o conhecimento das ciências, e especialmente das ciências naturais, era imprescindível. Para as camadas letradas, a ciência seria o veículo que colocaria a população no caminho para a civilização $\underline{\underline{25}}$

Naqueles anos da segunda metade dos oitocentos, alguns acontecimentos que impactaram o status quo brasileiro, como a Lei do Ventre Livre, que ampliou as discussões acerca da aproximação do fim da escravidão e da mão de obra que deveria ser utilizada no pós-abolição; o término da Guerra do Paraguai; o Manifesto Republicano de 1870, e a criação do partido republicano contribuíram para a desestabilização da monarquia. Nessa época, os debates iam de encontro às novas teorias cientistas/cientificistas europeias (como evolucionismo, naturalismo, darwinismo, positivismo, entre outras) que eram lidas e ressignificadas pela camada letrada do Brasil. Algumas dessas ideias foram exibidas e debatidas em conferências e cursos públicos, na cidade do Rio de Janeiro, nas décadas de 1870 e 1880.트

As conferências surgem no Brasil durante a passagem de Louis Agassiz pelo Rio de Janeiro, em 1865. Com 0

objetivo de conquistar um maior número de simpatizantes ao seu trabalho, o naturalista suíço apresentou suas ideias em 
conferências no Colégio Pedro II, recebendo o apoio do Imperador. Era uma novidade para os brasileiros, uma revolução nos seus hábitos. A maioria das conferências que passaram a ser realizadas eram públicas e nos vários locais onde ocorriam preleções falava-se sobre assuntos diversos, como cultura, economia, política e ciência.

As Conferências Populares da Glória receberam esse nome porque eram proferidas nas escolas públicas da freguesia da Glória, no município da Corte, na Praça Duque de Caxias (atual largo do Machado). Foram idealizadas pelo conselheiro Manoel Francisco Correia e iniciaram-se em 23 de novembro de 1873. Elas ocorriam duas vezes por semana; depois somente aos domingos, às 11 horas da manhã. Elas foram o primeiro espaço em que foram realizadas preleções de uma forma mais sistemática. Seu funcionamento estava sempre bastante vinculado à figura de Manoel Francisco Correia que, dentre outras coisas, era responsável por convidar os oradores. Eram conferências públicas e de entrada gratuita, sendo necessário apenas que se adquirisse o bilhete de entrada com antecedência. A entrega do bilhete era feita pelo conselheiro Manoel Francisco Correia e pelo orador do dia, o que mostra que o público que frequentava as conferências era bastante seleto, tendo em vista que este deveria integrar uma rede de relações sociais de classes elevadas.

Entre os anos de 1873 e 1889, ocorreram 602 preleções, sendo elas proferidas por 145 oradores. No primeiro momento, entre os anos de 1873 e 1880, houveram mais conferências - ao todo, 362. No ano de 1874, por exemplo, foi quando ocorreu o maior número de conferências (97). Após 1881, houve uma considerável diminuição do número de preleções, o que pode ser considerado como consequência do esgotamento do evento em si, por já não ser mais uma novidade, por conta da repetição de temas, entre outras razões.

Na Conferência inaugural, o Conselheiro Corrêa delimitou o mote principal das Conferências, ou seja, instruir 0 povo nos mais diversos assuntos. Todavia, deveriam ficar de fora os temas polêmicos, como aqueles que envolvessem questões políticas e religiosas. $\underline{\text {.7 }}$

De acordo com o conselheiro Correia, as conferências deveriam ser fraqueadas a todos, uma vez que o seu objetivo principal era a instrução do povo. No entanto, os relatos da época deixam transparecer que a sua plateia era constituída por um seleto público. $\underline{28}$

A forma como as conferências eram dispostas se assemelhava a um sistema escolar, onde se ensinavam as disciplinas em forma de cursos. Elas eram ministradas por pessoas que eram conhecedoras e autoridades nos assuntos discutidos. Mesmo as preleções que não estavam estruturadas dessa forma, tinham um caráter pedagógico. No entanto, as conferências não tinham a intenção de constituir-se como um espaço público alternativo ao sistema escolar. Elas podem ser compreendidas como um projeto educativo.

Os assuntos que eram apresentados nas conferências eram de suma importância para o público e estavam inseridos em projetos mais amplos de modernização nacional. Os oradores, em diversas exposições, faziam uso de um vocabulário científico/cientificista, ainda que o foco da preleção não fosse exatamente ligado à ciência A linguagem da ciência era a forma encontrada por esses estudiosos de veicular essa nova agenda de projetos modernizadores que estavam se formando. Foram variados os temas que foram abordados nas Conferências Populares da Glória, dentre os quais pode-se destacar os culturais (história, letras, teatro, educação, literatura, geografia) e os relativos à ciência (medicina, matemática, ciências naturais, ciências físicas).

A medicina foi 0 assunto mais frequente na tribuna da Glória. Nessa categoria, aparecem conferências que tratavam de moléstias, da profissão e do ensino médico, discussões sobre variadas substâncias, anatomia, fisiologia, e aquelas em que as análises e argumentos foram embasados no discurso médico. Doenças como a tuberculose, a cólera e a febre amarela. Um dos momentos mais importantes foi quando no ano de 1880 um grupo de médicos da Faculdade de Medicina do Rio de Janeiro (FMRJ) subiu a "tribuna da Glória" para comentar sobre as precariedades do ensino médico no país e propor reformas. ${ }^{29}$

Os cursos públicos e as conferências se organizaram como espaços de sociabilidade letrada e científica. Participar desses eventos, seja como orador ou como espectador, fazia com que o indivíduo se inserisse em uma determinada 
rede social, e, assim, aumentava o capital social e cultural desse personagem. Os oradores que se apresentavam eram dotados de capital simbólico, que naquele contexto era visto como fama, prestígio. Muitas dessas pessoas atraíam público só por serem elas a discursas, independente do tema/assunto que fosse abordado. A presença de um público que também detinha capital simbólico ajudava ainda mais a impulsionar, consagrar e legitimar a importância da conferência Sempre que o Imperador se fazia presente em alguma conferência, a imprensa logo tratava de destacar a "augusta presença", tendo em vista que este seria uma encarnação máxima desse capital simbólico. Ao declamar seus discursos públicos, os oradores também aumentavam seu capital simbólico.

0 público que frequentava essas conferências, independente de seu perfil, estabelecia relações sociais nesses locais, pois assistir as preleções seria também uma forma de ampliar seu capital cultural. Era importante para este público letrado estar presente em tais eventos, por vários motivos: o Imperador poderia estar presente, o que faria com que o indivíduo mostrasse que estava em sintonia com o que a casa imperial valorizava e apreciava; mostrar para 0 resto da sociedade que estava atento às novidades tecnológicas e científicas da atualidade; e, ainda, aproveitar 0 momento de entretenimento para encontros sociais com membros dessa mesma elite letrada. Era características dessas conferências serem espaços de sociabilidade nos quais muito do que era ali exposto também seria tema de debate em outros ambientes letrados.

Desde o começo, as Conferências Populares da Glória receberam enorme repercussão na imprensa. Na sua inauguração, durante o seu funcionamento e nos discursos ali proferidos, a imprensa sempre esteve presente através dos jornais que noticiavam esses acontecimentos. A aceitação ou não do público das ideias ali expostas iria depender de como estas repercutiriam na imprensa. E o acolhimento do público às Conferências Populares era tão grande que, no ano de 1874, em um artigo enviado ao 0 Globo, um leitor sugeriu a aquisição de um taquígrafo, para publicar e conservar as Conferências. Posteriormente, com o sucesso e aceitação das Conferências, foram contratados dois taquígrafos para efetuarem os registros. "0 uso da taquigrafia significava que o saber seria retido a partir de então, registrado de forma impressa e escrita, haveria a cristalização do saber proferido". 30 Com a transcrição, a partir de 1876, as Conferências passaram a ser impressas numa revista mensal chamada Conferencias Populares. A revista Conferências Populares era vendida aos assinantes e distribuída para a imprensa local. As pessoas que residiam fora da corte e queriam adquirir ou assinar o periódico deveriam enviar um envelope com o dinheiro ao escritório da empresa.

Para além da publicação da revista supracitada, conforme lembrou Maria Rachel Fróes da Fonseca, os periódicos da época, como Jornal do Commercio, Diário do Rio de Janeiro, Gazeta de Notícias, entre outros, informavam sobre 0 dia da sua realização (aviso) e as reproduziam na íntegra ou sob a forma de resumo. $\frac{31}{1}$

Para as elites letradas brasileiras do fim do século XIX, civilização e progresso eram palavras recorrentes em seus discursos inflamados. Civilizar e educar a população era uma tendência do Império, especialmente no seu projeto de modernização. Ser civilizado era o ápice que uma sociedade poderia alcançar através do conhecimento das leis, na suavidade dos costumes e no desenvolvimento intelectual, artístico e industrial da nação.

0 progresso seria ascender rumo à perfeição, seria o crescimento civilizacional que resultaria na felicidade do homem. Manoel Francisco Correia, quando idealizou as Conferências Populares da Glória, chamou atenção para a importância da instrução social que faria com que a população do Brasil caminhasse em direção à civilização. Para isso, era importante diminuir os crimes, manter a união física do país e fazer prosperar o comércio e a indústria.

Nesse período, muitos intelectuais introduziram em seu campo semântico a ideia de "vulgarização". Na ciência, pressupõe-se uma ideia de tradução, onde seria possível transformar discursos científicos, cheios de termos e conceitos dotados de enorme complexidade em uma linguagem mais simples e acessível para a população leiga. Dessa forma, vulgarizar seria

Tornar algo extremamente conhecido e tinha como sinônimos propagar, divulgar e popularizar. Todavia, no período abordado neste trabalho, o termo mais utilizado era 'vulgarização'. A acepção 'traduzir em vulgar' não possui o caráter depreciativo atual, pois, de acordo com o mesmo dicionário, uma das significações de 
vulgar era 'divulgar, vulgarizar, fazer público, tornar conhecido pela palavra ou por escrito', sendo, dessa maneira, sinônima de 'vulgarizar'. Partindo dessas concepções, vulgarizar as ciências em fins do século XIX, no Brasil, seria torná-la pública, muito conhecida, colocando-a ao alcance de todos ou, ao menos, de uma grande parcela da população. $\underline{32}$

As conferências eram, dessa forma, espaços de vulgarização da ciência. Contudo, essa vulgarização não era estendida à toda população, mas apenas para uma pequena parcela letrada da sociedade. Na realidade, tratava-se de um projeto político que fazia com que a maior parte da população fosse excluída da cidade do Rio de Janeiro. A intenção dos homens letrados que palestravam nos espaços públicos de vulgarização científica era difundir o conhecimento científico para seus pares. As conferências, e também os cursos públicos, apresentavam, de fato, modernos projetos civilizacionais, mas não atuantes de forma prática na sociedade, civilizando diretamente àqueles que eram chamados de bárbaros.

\section{Os Cursos de Botânica Popular de Joaquim Monteiro Caminhoá}

Seguindo o objetivo principal preconizado pelo conselheiro Correia de levar a instrução ao povo, Joaquim Monteiro Caminhoá apresentou a proposta de um Curso de Botânica Popular, que foi proferido num total de dezessete aulas no ano de 1876 no âmbito das Conferências da Glória.

As Conferências tinham como objetivo vulgarizar o estudo das ciências naturais e da botânica. Caminhoá realizou essas conferências buscando levar à população, especialmente para aquele público que não era privilegiado ou familiarizado com esse conhecimento, essa "dádiva" que é o contato com a terra, com a natureza, com as plantas, com as flores etc. Para ele, era fundamental que todo o Brasil tivesse alguma aproximação com esses estudos, que todos tivessem noção desses conhecimentos relacionados às ciências naturais, especialmente por ser um país de tradições agrícolas e que concentrava suas principais riquezas na agricultura. Segundo Caminhoá, era imprescindível que cada povo educasse seus filhos de modo que favorecesse as aptidões mais úteis ao progresso e prosperidade do país. Para ele, seria importante criar o gosto pela agricultura, pela botânica e pelas ciências naturais desde a infância.

A primeira vez que Caminhoá foi à Tribuna da Glória ocorreu na data de 26 de julho de 1874, para apresentar a conferência de n. 65, intitulada Sociedade de Socorro aos Feridos e Doentes Militares. Por sua vez, uma segunda participação se deu quatro dias depois da primeira (30/07), conferência de n. 66, intitulada Influência da Mulher nas Guerras Modernas.

Por sua vez, o Curso de Botânica Popular teve início na data 10 de agosto de 1876, num total de dezessete aulas, sendo que dez foram de responsabilidade de Caminhoá, e as outras sete restantes foram proferidas por Francisco Ribeiro de Mendonça ${ }^{3}$. 


\begin{tabular}{l|l|l|l} 
Ano & Dia e Mês & Conferencista & Tema \\
1876 & $10 / 08$ & Joaquim Monteiro Caminhoá & Curso de Botânica Popular I. \\
\hline 1876 & $02 / 09$ & Joaquim Monteiro Caminhoá & Curso de Botânica Popular II. \\
\hline 1876 & $08 / 09$ & Joaquim Monteiro Caminhoá & Curso de Botânica Popular III. \\
\hline 1876 & $14 / 09$ & Joaquim Monteiro Caminhoá & $\begin{array}{l}\text { Curso de Botânica Popular IV. } \\
\text { Do microscópio e seu emprego no estudo da anatomia } \\
\text { das plantas, células, sua composição e modificações. }\end{array}$ \\
\hline 1876 & $21 / 09$ & Joaquim Monteiro Caminhoá & $\begin{array}{l}\text { Curso de Botânica Popular V. } \\
\text { Das células, formando tecidos e órgãos. }\end{array}$ \\
\hline 1876 & $28 / 09$ & Joaquim Monteiro Caminhoá & $\begin{array}{l}\text { Curso de Botânica Popular VI. } \\
\text { Da raiz e do caule. }\end{array}$ \\
\hline 1876 & $05 / 10$ & Joaquim Monteiro Caminhoá & $\begin{array}{l}\text { Curso de Botânica Popular VII. } \\
\text { Dos órgãos que são a transição entre a raiz e o caule. }\end{array}$ \\
\hline 1876 & $14 / 10$ & $\begin{array}{l}\text { Joaquim Monteiro Caminhoá } \\
\text { (substituído por Francisco } \\
\text { Ribeiro de Mendonça). }\end{array}$ & $\begin{array}{l}\text { Curso de Botânica Popular VIII. } \\
\text { A folha. }\end{array}$ \\
\hline 1876 & $27 / 10$ & Joaquim Monteiro Caminhoá & $\begin{array}{l}\text { Curso de Botânica Popular IX. } \\
\text { A folha. }\end{array}$ \\
\hline
\end{tabular}

Do conjunto total do Curso de Botânica, apenas duas conferências foram publicadas: o Curso de Botânica Popular I, realizado na data de 10 de agosto de 1876; e o Curso de Botânica Popular IÍ, realizado na data de 02 de setembro de 1876. Os demais soubemos que aconteceram por meio dos avisos nos jornais da época que noticiavam as Conferências.

\section{O Curso de Botânica Popular I}

Caminhoá iniciou o primeiro Curso apresentando de imediato o seu objetivo primordial, que era o de fazer propaganda das ciências naturais, levando-a a grupos sociais que não tinham acesso ao ensino das mesmas. Assim argumentou:

Meu fim principal é o fazer propaganda em relação ás ciências naturais, principalmente para o sexo feminino e classes que não são propriamente obrigadas a esse estudo por lei, compreendereis certamente que é desculpável tanta ousadia minha [...] em um país conhecido como o paraíso dos naturalistas, em um país onde a principal fonte de riqueza é a agricultura, que certamente não tem outra base que não as ciências naturais e físicas, compreendeis a necessidade não de quatro ou cinco, mas de centenas de cursos de botânica. ${ }^{34}$

Caminhoá prosseguiu argumentando que as ciências naturais deveriam ser estudadas "por toda parte no Brasil". Mais uma vez ele reitera a importância da "vulgarização dos conhecimentos das ciências naturais, e principalmente da botânica", e argumentou que as ciências não deveriam ficar restritas apenas aos espaços acadêmicos, como a

Escola Politécnica, na Faculdade de Medicina, no Museu e no Colégio Pedro II. Demais, o atual curso do Museu ocupa-se de botânica geral; o da Faculdade de Medicina de botânica médica; o da Escola Central de botânica aplicada ás construções; o do Colégio de Pedro II, resumido como convém, conta limitado numero de alunos, ficando por conseqüência vários ramos, tais como a botânica agrícola, a botânica industrial e outros sem ser ensinados [...] cada um dos professores (da Faculdade de Medicina e da Politécnica) não tem suficiente tempo para dar conta da sua tarefa. $\frac{35}{5}$ 
Caminhoá argumentou que deveríamos iniciar os brasileiros nos conhecimentos da Botânica pelo lado mais "belo e útil", afastando todas as "dificuldades sanáveis", a fim de que se conseguisse propagar o estudo das plantas e vegetais, bem como 0 das outras ciências naturais. E, sugeriu que tais estudos deveriam começar já nas escolas primárias, e não apenas nos cursos superiores:

Julgo que deveremos fazer com que até nas escolas primarias publicas sejam ensinados os rudimentos destas ciências [...] não ha inconveniente algum em fazermos com que as crianças em vez de recitarem somente Camões, Frei Luiz de Sousa ou D. João de Castro, etc., recitem alguma coisa também relativa ás ciências naturais, como se faz hoje nos bons colégios ingleses, suecos, etc.

A seguir, comentou sobre a linguagem e metodologia que iria imperar no Curso de Botânica Popular:

Como vos prometi, procurarei o mais possível no meu curso torná-lo prático e agradável; para o que afastarei os espinhos e dificuldades da botânica pura ensinada pela máxima parte dos sábios, cujas preleções servem mais para professores, do que para o povo [...] como geralmente se acredita, o estudo desta bela ciência, que é antes um assunto para as damas e para as almas sensíveis e bem formadas, do que para as que não são [...] a botânica é a ciência para todas as idades, e para todos os caracteres, contanto que o individuo tenha pelo menos inteligência comum, e um pouco de coração. $\frac{3 z}{2}$

No Curso de Botânica Popular I, Caminhoá se preocupou em apresentar as "fases da Botânica". Ele argumentou que no início era exclusivamente estudada pelos "sábios e sacerdotes dos velhos tempos, que faziam tudo por não a divulgar, com o interesse de tornarem-se admirados do povo". E, o mesmo se sucedia nos demais ramos do conhecimento, pois "a linguagem que falavam e em que escreviam a ciência era quase cabalística! Não se compreendiam as coisas como deviam ser compreendidas"..$\underline{38}$ Os cursos de Botânica eram frequentados pelos que se "dedicavam aos altos estudos; e, portanto, se achavam nas condições especiais de poder compreender a linguagem técnica dos sábios. Quando, por exemplo, queriam falar da rosa comum diziam eles Rosa centifolia seu multiplicispetalis..." . $\underline{39}$

Caminhoá argumentou que foi o naturalista sueco Carl von Linné (1707-1778), ou Lineu, quem teve como objetivo vulgarizar as ciências da natureza ao propor uma nova nomenclatura para as plantas e os vegetais, substituindo "a maldita coleção dificílima de expressões técnicas sem necessidade". De acordo com o autor,

Linneu foi o primeiro que propriamente teve de lutar contra seus contemporâneos, que entediam dever empregar nomes de seus amigos e conhecidos de origem germânica, céltica, teutônica para designar as plantas novamente descobertas! Abuso contra o qual severamente clamava o grande sueco que se apresentou com denodo invejável, e lutando até que conseguiu estabelecer a sua nomenclatura. $\underline{\underline{4}}$

\section{E prosseguiu:}

A luta que ele teve de sustentar foi por duas razões; a primeira, porque teve de desfazer tudo quanto os autocratas das ciências naturais tinham feito; a segunda porque tinha de erigir um edifício completamente novo sobre as ruínas da Babel criada por seus antecessores e coevos. ${ }^{11}$

A seguir, Caminhoá explicou o método aplicado à nova nomenclatura da sistemática de classificação elaborada por Lineu:

Linneu começou por propor que os termos de origem que não a latina, língua da ciência então, e ainda hoje, fossem substituídos por outros ao mesmo tempo eufônicos, de fácil pronunciação e curtos; devendo constar de duas palavras apenas. Citarei alguns exemplos. Rosa centifolia ou de cem folhas; Asedinhapratense ou do prado; Trigo cultivado; Malva officinal; Violeta cheirosa, etc. 
Assim foi explicando as leis da nomenclatura biológica e as classificações pela maneira mais singela e conveniente.

Estabeleceu que os nomes dos gêneros fossem substantivos, e os das espécies adjetivos e que indicassem alguma das propriedades da nova planta classificada.

Assim como no homem pelo nome próprio e pelo nome de família se conhecem milhões de pessoas, assim também nos seres botânicos e zoológicos, disse ele, se pode perfeitamente pelo nome do gênero e da espécie, conhecer o tipo. $\underline{42}$

Convém sublinhar que o naturalista Lineu, por meio do seu Systema Naturae (1758), estabeleceu um método que definia ser o olho o responsável por realizar o primeiro gesto do conhecimento, uma vez que seria necessário ter visto primeiro 0 objeto para depois nomeá-lo. $\frac{43}{}$

A linguagem que Lineu optou por estabelecer para a classificação dos animais compreendia dois nomes latinos, um ligado ao gênero, outro à espécie. 0 seu sistema de classificação apresentava-se dividido em quatro níveis categóricos: classe, ordem, gênero e espécie. 0 gênero foi a pedra angular da classificação lineana. ${ }^{44}$ De acordo com Sloan ${ }^{45}$, Lineu se inscrevia em uma ampla tradição classificatória que remontava aos trabalhos de Cesalpino, John Ray e Tournefort, em que as estruturas reprodutoras serviam para a classificação das plantas, e ampliou os usos anteriores de Wotton, Francis Willughby e Ray, que utilizavam as partes locomotoras e funcionais para a definição e classificação dos principais grupos de animais.

Por sua vez, o aparelho reprodutor foi a parte anatômica escolhida para os seus estudos, ficando seu método conhecido como o "sistema sexual". A reprodução, para ele, indicava o secreto plano operativo do criador. As outras partes eram vistas como irrelevantes para o efeito de classificação, assim como o contorno ambiental, e outras características consideradas pouco importantes, como a cor. 0 assunto foi apresentado pela primeira vez em forma de esquema no Systema Naturae. Quatro critérios básicos foram estudados: número, forma, proporção e situação. 0 número absoluto era assim apenas um dos conjuntos de caracteres de Lineu. Entre os caracteres que ele utilizou para distinguir 24 classes, incluíam-se questões como, se as flores eram visíveis ou não, quantos estames e pistilos há, se eles se fundem ou não, se ocorrem ou não os elementos masculino e feminino na mesma flor. As classes, por sua vez, eram divididas em ordens, com o auxílio de caracteres adicionais.

O sistema lineano era extremamente artificial, mas possuía um caráter marcadamente útil para os fins práticos de identificação, e para a reserva e recuperação de informações. A tradição lineana basicamente se ocupou de coletar, classificar e desenvolver um sistema natural de classificação. Uma classificação era um sistema que permitia ao botânico conhecer as plantas, ou seja, dar-Ihes um nome, com rapidez e segurança. A sua preocupação era de ordem prática, com o objetivo de identificação. Ele enfatizou os aspectos do procedimento taxonômico que pudessem facilitar a identificação. 0 sistema de Lineu supunha uma concepção estática da natureza, segundo a qual as formas existentes correspondiam às criadas inicialmente. 0 seu propósito era congruente com a idéia da natureza como obra acabada. Essa visão inseria-se na vertente da história natural que se convencionou chamar de classificatório-descritiva. $\underline{46}$

Lineu aplicou os princípios taxonômicos estabelecidos por ele para a botânica e, também, para o reino mineral. Por sua vez, ele restaurou o latim em sua nomenclatura taxonômica e deu início a um projeto a ser realizado no mundo da forma mais concreta possível. Na medida em que sua taxonomia se difundiu por toda a Europa na segunda metade do século XVIII, os naturalistas a ele ligados espalhavam-se por todo o planeta, coletando plantas e insetos, medindo, preservando, fazendo desenhos e tentando levar tudo isso para casa. Depois, a informação era disponibilizada em livros, as espécies mortas eram inseridas em coleções de história natural, e as vivas eram aclimatadas nos hortos botânicos. ${ }^{47}$

Dando sequência à análise do estudo, Caminhoá dividiu a história da Botânica em três fases: antiguidade; a descoberta do microscópio; e, a descoberta da América. Essas fases da história da botânica foram bastante marcantes, pois aprofundaram o conhecimento e apresentaram novos objetos de estudo. Joaquim Monteiro Caminhoá preocupava-se com um estudo da botânica menos tedioso e mais divertido. 
Caminhoá iniciou sublinhando que nos "velhos tempos" o conhecimento da Botânica era simples, superficial. Ele chamou atenção para o fato de que antes da descoberta do microscópio, as ciências naturais (especialmente, a Botânica) limitava-se àquilo que a vista do observador podia contemplar e reconhecer. Contudo, ele destacou que essa parte é menos essencial, porque é na célula que se encontra a resolução dos problemas da biologia ou das funções animais e vegetais.

Foi apenas depois do século XV, que o uso do microscópio passou a ser aplicado à Botânica, o que foi uma verdadeira revolução nos estudos das ciências naturais. Caminhoá destacou que 0 uso desse equipamento trouxe 0 "ridículo" ao trabalho dos pesquisadores, pois a partir do uso do microscópio e do contato com o recém-descoberto "mundo dos micro-organismos" os estudiosos diziam que podiam ver coisas que os outros não viam. ${ }^{48}$ Foi graças ao microscópio que se descobriu a célula, por exemplo, que foi o ponto de partida para o conhecimento da organização e das funções dos seres naturais.

A descoberta da América, segundo Caminhoá, foi outro momento de virada na história das ciências naturais, pois significou o contato dos povos europeus com zonas extensas, férteis, ricas em diversidade de plantas e animais, além de outras riquezas oriundas do solo. Vale destacar o impacto causado nos naturalistas ao se depararem com as florestas virgens seculares do continente americano, povoada por aves, insetos multicoloridos e outros animais raríssimos que jamais haviam sido observados pelos pesquisadores europeus. Além das terras banhadas pelos vastos rios - que eram "verdadeiros oceanos de água doce" - e as delirantes ilhas flutuantes.

0 Novo Mundo, recheado de descobertas e histórias fantásticas - muitas delas mais ficção que realidade -, criaram nos pesquisadores, naturalistas, exploradores europeus o interesse pela aventura que se configurava desbravar o "paraíso" recém descoberto. 0 número de seres classificados pelos cientistas naturais, nesse período, segundo Caminhoá, cresceu consideravelmente.

\section{O Curso de Botânica Popular II}

No Curso de Botânica Popular II, Caminhoá argumentou sobre a importância das ciências naturais para o Brasil. E, se propôs a apresentar um "resumo histórico da Botânica no Brasil", assunto que pouco se encontrava nos nossos livros de história, uma vez que "disso bem pouco se cuida ainda entre nós". Lamentou que no Brasil ainda não se sabia com certeza sobre a importância das Ciências Naturais, "apesar de dever estar na consciência de todos que ninguém pode hoje ignorar completamente essas ciências que servem de alicerces, por assim dizer, ao principal cabedal instrutivo de qualquer que tenha regular educação!". $\underline{49}$

Caminhoá dividiu a história das ciências naturais brasileiras, e principalmente da Botânica no Brasil, em quatro fases: período colonial (período em que o Brasil encontrava-se abaixo de quase todas as outras colônias), regência e reinado de D. João VI (que ampliou os estudos das ciências naturais no Brasil, especialmente com a criação do Jardim Botânico), regência e reinado de D. Pedro I (marcado pela vinda de diversos especialistas, principalmente da Áustria por circunstância do casamento do monarca com a Imperatriz Leopoldina) e a época moderna (marcada por diversos progressos no Brasil).

Sobre o período colonial, Caminhoá comentou que aquele momento foi um espaço de vazio científico. A principal preocupação voltava-se para a obtenção de riquezas:

Durante a fase de sua vida colonial o Brasil esteve muito abaixo do nível intelectual de quase todas as outras colônias, cujas metrópoles se ocupavam mais com os seus progressos. Enquanto a Europa preparava esquadras para fazer descobertas e exércitos para novas conquistas, as colônias ficaram esquecidas; e vos deveis lembrar, porque a historia com eloquência no-lo diz, que foi justamente na época das guerras da África e conquistas das Indias que houve a casual descoberta do Brasil por Cabral em Abril de 1500, ou, como querem outros, por Pison em Janeiro daquele mesmo ano. Pois bem, nos tempos coloniais apenas cuidava-se 
dos produtos comerciais lucrativos, em cujo numero se achava o pau-brasil. A extração dos diamantes, do ouro e outros metais preciosos, era a principal preocupação do governo metropolitano..$^{50}$

Contudo, num determinado momento da colonização começou-se, segundo Caminhoá, a estudar a Botânica, fato que ocorreu no período das invasões francesas, quando Villegagnon (Nicolas Durand de Villegagnon,1510-1571) por aqui aportou e trouxe Jean de Léry (1534-1611), que segundo Caminhoá, foi o "foi o primeiro que começou a fazer tentativas no sentido de estudar nossas riquezas naturais". .51

Num segundo momento, Caminhoá sublinhou o período da colonização batava na região da América Portuguesa, quando junto com Maurício de Nassau veio uma comissão de sábios e letrados, dentre os quais Guilherme Piso (16111678) e outro George Marcgraf (1610-1644).

0 segundo período refere-se ao reinado de Dom João VI, momento em que no ano de 1808 a monarquia portuguesa fugindo das invasões francesas, fixou a sua sede na América Portuguesa, e passou a ter como sede a cidade do Rio de Janeiro, a nova capital do império português. De acordo com Caminhoá, o monarca trouxe "consigo pessoal capaz de fazer com que a infeliz colônia pudesse conseguir melhoramentos [...] N'essa época houve algum progresso nos diferentes ramos de conhecimentos humanos, e portanto nas ciências naturais". . $2^{2}$ Dentre as inovações mencionadas por Caminhoá estavam a criação do Jardim Botânico e o Museu Real.

Um terceiro momento diz respeito ao reinado de D. Pedro I, em particular ao momento do seu casamento com a Imperatriz D. Leopoldina, nascida arquiduquesa da Áustria, princesa da Hungria e da Boêmia. Tal fato incrementou consideravelmente "os progressos destes ramos das ciências naturais", uma vez que na ocasião ocorreu a "vinda de vários botânicos e zoologistas eminentes d'Austria, Baviera e Italia, afim de estudarem nossa flora e fauna". Segundo Caminhoá, o Imperador ordenou no ano de 1817 que os sábios que para cá vieram fossem estudar as nossas riquezas naturais, "época brilhante para a botânica no Brasil, mas não do Brasil". A comissão austro-bavara-italiana se ocupou de estudar a Botânica e a Zoologia, ganhando destaque os naturalistas Spix e Martius. Segundo Caminhoá, eles estudaram também as línguas indígenas, "de forma que puderam prestar um valioso contingente para a confecção de um dicionário das línguas dos aborígenes do Brasil". .53

Caminhoá também sublinhou neste período a atuação do ministro José Bonifacio de Andrada e Silva, que era naturalista e professor em Coimbra, e, na ocasião, "as ciências naturais fizeram algum progresso também entre nós". 54

E, por fim, após a fase do governo do Imperador D. Pedro I, Caminhoá mencionou dois botânicos que vinham contribuindo para "os progressos da época científica actual": Frei Custódio Alves Serrão (1799-1873), e Francisco Freire Alemão de Cisneiros (1797-1874). Caminhoá justificou a escolha dos dois nomes por serem "conhecidos em todo o país, e mesmo na Europa, e que dos tempos modernos são os únicos que merecem ser citados como botânicos propriamente tais".$\underline{55}$

Dando prosseguimento, Caminhoá apresentou uma vasta lista de nomes de naturalistas que estiveram no Brasil desde 0 ano de 1500 até 0 de 1845, e, depois, uma relação dos principais navios que vieram ao Brasil trazendo botânicos, naturalistas ou colecionadores.

Após concluir a parte da história da Botânica no Brasil, Caminhoá, na parte final da conferência, se debruçou em diferenciar os vegetais dos animais e explicar as diferentes partes que compõem um vegetal, como caule, eixo da planta, rizoma, raiz, folha, flor, fruto e semente.

Num determinado momento teceu considerações sobre a natureza, em particular sobre as plantas, uma vez que tais seres vivos "abrandam os costumes, convidam á oração e aproximam o homem de Deus; mas de um modo muito diferente daquele que a crença pura, mas sem a convicção profunda poderia fazê-lo?" . 6 E, prosseguiu: "Os poemas que se baseiam no estudo da natureza são, como a própria natureza, simples e admiráveis: elevam o coração e a inteligência até 0 arroubo! Deixai que digam que o naturalista é materialista, porque em nossas consciências bem sabemos que não!" ${ }^{57}$

A seguir, argumentou que o estudo dos seres criados por Deus nos leva ao estudo do Criador. E, nesse momento, considerou sobre aquilo que diferencia o trabalho do naturalista daquele realizado pelo teólogo: 
O que separa o naturalista do teólogo puro é principalmente o modo de compreender a obra grandiosa do Ser Supremo. O primeiro como o segundo ama-o e se abraça com Ele e pasma ante a perfeição da criação em sua simplicidade sublime e harmonia de suas leis criando o homem com a mesma facilidade que de uma célula criou a planta; o segundo fazendo-o preparar o universo com tudo quanto o homem pode precisar, e ocupasse cada dia de uma coisa, destinada somente ao nosso bem estar! $\frac{158}{\square}$

Os dois textos analisados se inserem, como já afirmamos, no Curso de Botânica Popular apresentado por Caminhoá no âmbito das Conferências Populares da Glória. Eles se constituem como fontes importantes no que se refere à vulgarização das ciências no Império do Brasil, que ocorreu não apenas por meio da imprensa, mas também em espaços não-institucionais, como o da "Tribuna da Glória".

\section{Considerações finais}

Joaquim Monteiro Caminhoá foi um dos mais importantes homens de ciência do Império do Brasil. Ele atuou em importantes espaços institucionais como a Faculdade de Medicina do Rio de Janeiro, e o Imperial Colégio de Pedro II, locus de ensino e pesquisa. Integrou os quadros de importantes academias científicas, bem como publicou diversos artigos e livros. Preocupou-se com a vulgarização das ciências, uma vez que partilhava da concepção de que as "luzes" do conhecimento científico deveriam ser espalhadas pela sociedade. Seguindo essa diretriz participou das Conferências Populares da Glória, espaço onde ficou responsável por ministrar um Curso de Botânica Popular. Foi um estudioso que seguia os ditames da ciência moderna, experimental e aplicada, contribuindo assim para o processo de emergência e consolidação das ciências naturais no Brasil do oitocentos.

\section{Notas e referências bibliográficas}

Alex Gonçalves Varela é professor de história na Universidade do Estado do Rio de Janeiro (UERJ). E-mail: alexvarelarj@terra.com.br

1 Esta pesquisa teve 0 apoio da FAPERJ.

2 Sobre a literatura produzida a respeito de Caminhoá ver: VARELA, Alex Gonçalves. Joaquim Monteiro Caminhoá: um médico ilustrado do Império do Brasil, 1858-1896. História, Ciências, Saúde - Manguinhos. Rio de Janeiro, v.26, n.1, jan.-mar. 2019, pp. 335-345.

3 Casa de Oswaldo Cruz / Fiocruz. Dicionário Histórico-Biográfico das Ciências da Saúde no Brasil (1832-1930). Verbete Escola de Cirurgia da Bahia. In: http:// www.dichistoriasaude.coc.fiocruz.br (Acessado no dia 11/11/2018).

4 FERREIRA, Luís Otávio. João Vicente Torres Homem: Descrição da Carreira Médica no Século XIX. PHYSIS - Revista de Saúde Coletiva. Rio de Janeiro, vol. 4, n. 1, p. 68, 1994.

$5 \quad$ Idem, p. 69

6 KURY, Lorelai Brilhante. Francisco Freire Alemão, Botânico e Viajante. In: KURY, Lorelai Brilhante. (Org.) Comissão Científica do Império, 1859-1861. Rio de Janeiro: Andrea Jakobsson Estúdio Editorial, 2009.

7 Casa de Oswaldo Cruz / Fiocruz. Dicionário Histórico-Biográfico das Ciências da Saúde no Brasil (1832-1930). Verbete Escola Anatômica, Cirúrgica e Médica do Rio de Janeiro. In: http://www.dichistoriasaude.coc.fiocruz.br (Acessado no dia 11/11/2018).

8 FERREIRA, 1994, op. cit., p. 67.

9 Sobre os hortos botânicos no Império, em particular sobre o estudo realizado por Caminhoá conferir: BEDIAGA, Begonha. Marcado Pela Própria Natureza. 0 Imperial Instituto Fluminense de Agricultura, 1860 a 1891. Rio de Janeiro: FGV Editora; FAPERJ, 2014.

10 SÁ, Magali Romero. 0 botânico e o mecenas: João Barbosa Rodrigues e a ciência no Brasil na segunda metade do século XIX. História, Ciências, Saúde Manguinhos. Rio de Janeiro, vol. VIII (suplemento), 2001. pp. 899-924.

11 FERREIRA, Luis Otavio.; MAIO, Marcos Chor; e AZEVEDO, Nara. 'A Sociedade de Medicina e Cirurgia do Rio de Janeiro: a gênese de uma rede institucional alternativa'. História, Ciências, Saúde — Manguinhos. Rio de Janeiro, vol. IV, n. 3, nov. 1997-fev. 1998, pp. 480-81.

12 EDLER, Flávio Coelho. A medicina no Brasil Imperial: fundamentos da autoridade profissional e da legitimidade científica. Anuario de Estudios Americanos. Sevilha, v. 60, n. 1, p. 141, 2003.

13 Sobre a Sociedade Velosiana conferir: LOPES, Maria Margaret. O Brasil Descobre a Pesquisa Científica. As Ciências Naturais e os Museus no Brasil no Século XIX. São Paulo: Editora HUCITEC, 1999.

14 Casa de Oswaldo Cruz / Fiocruz. Dicionário Histórico-Biográfico das Ciências da Saúde no Brasil (1832-1930). Verbete Sociedade Velosiana de Ciências 
Naturais. In: http://www.dichistoriasaude.coc.fiocruz.br (Acessado no dia 16/11/2018).

DIAS, Maria Odila da Silva. Aspectos da llustração no Brasil. Revista do Instituto Histórico e Geográfico Brasileiro. Rio de Janeiro, v.278, 1969.

Sobre uma listagem das publicações de Caminhoá conferir: Casa de Oswaldo Cruz / Fiocruz. Dicionário Histórico-Biográfico das Ciências da Saúde no Brasil (1832-1930). Verbete Joaquim Monteiro Caminhoá. In: http://www.dichistoriasaude.coc.fiocruz.br (Acessado no dia 16/11/2018).

CAMINHOÁ, Joaquim Monteiro. Elementos de Botânica Geral e Médica. Vol. 1. Rio de Janeiro: Tipografia Nacional, 1877. P. VII.

Idem, p. VII.

0 parecer foi emitido na data de seis de fevereiro de 1873, pelos professores Ezequiel Correa dos Santos, José Thomaz de Lima, e Manoel Maria de Morais e Vale.

CAMINHOÁ, 1877, op. cit., pp. VIII-IX.

Idem, p. IX.

Idem, p. X

Idem, p. X.

Idem, p. XI.

CARULA, Karoline. A Tribuna da Ciência - As Conferências Populares da Glória e as discussões do darwinismo na imprensa carioca (1873-1880). São Paulo: Annablume, 2009. p. 27.

CARULA, Karoline. Darwinismo, raça e gênero - Projetos modernizadores da nação em conferências e cursos públicos (Rio de Janeiro, 1870-1889). Campinas: UNICAMP, 2016. p. 28.

CARULA, 2009, op. cit., p. 29.

CARULA, 2016, op. cit., p. 55.

FONSECA, Maria Rachel Fróes da. As “Conferências Populares da Glória": A Divulgação do Saber Científico. História, Ciências, Saúde - Manguinhos. Rio de Janeiro, vol. II, n. 3, novembro de 1995-janeiro de 1996, p. 136.

CARULA, 2009, op. cit., p. 59.

FONSECA, 1995, op. cit., p. 137.

CARULA, 2016, op. cit., p. 81.

FONSECA, 1995, op. cit., pp. 152-155.

CAMINHOÁ, Joaquim Monteiro. Curso de Botânica Popular I. In.: Conferências Populares. Rio de Janeiro: Typ. Imp. e Const. de J. Villeneuve \& C., 1876. p. 74. Idem, p. 74.

Idem, pp. 80-1.

Idem, p. 81.

Idem, p. 82.

Idem, pp. 82-3.

Idem, p. 84.

Idem, p. 84.

Idem, pp. 84-5.

FOUCAULT, Michel. As palavras e as coisas: uma arqueologia das ciências humanas. São Paulo: Martins Fontes, 1990.

MAYR, Ernest. 0 Desenvolvimento do Pensamento Biológico: Diversidade, Evolução e Herança. Brasília, DF: Ed. UnB, 1998. p. 208.

SLOAN, Phillip R. Historia Natural, 1670-1802. In: OLBY, R.; CANTOR, G. N.; CHRISTIE, J. R. R.; HODGE, M. J. S. (Ed.). Companion to the History of Modern Science. London and New York: Routledge, 1996. p. 48.

MAYR, 1990, op. cit., p. 206.

KOERNER, Lisbeth. Carl Linneus in his time and place. In: JARDINE, N.; SECORD, J. A.; SPARY, E. C. (Ed.). Cultures of Natural History. Cambridge: Cambridge University Press, 1997.

CAMINHOÁ, Joaquim Monteiro. Curso de Botânica Popular l., 1876, op. cit., p. 86.

CAMINHOÁ, Joaquim Monteiro. Curso de Botanica Popular II. In.: Conferencias Populares. Setembro, n. 9, ano de 1876. Rio de Janeiro: Typ. Imp. e Const. de J. Villeneuve \& C, 1876, p. 4.

Idem, p. 5.

Idem, pp. 6-7.

Idem, pp. 9-10.

Idem, pp. 10-11.

Idem, p. 11.

Idem, pp. 11-12.

Idem, p. 29.

Idem, p. 29.

Idem, p. 29.

[Artigo recebido em Janeiro de 2020. Aceito para publicação em Maio de 2020] 